\title{
PATENT ENFORCEMENT: A COMPARATIVE REVIEW PREVENTING PATENT TROLLING IN EUROPE
}

\author{
Benjamin FRANCO, Cristian BANACU \\ Academy of Economic Studies, Bucharest, Romania \\ e-mail: bfranco01@yahoo.com
}

\begin{abstract}
The US has made significant progress in the patent legislation landscape as evidenced by the US Patent Act in the Constitution and America Invents Act (AIA) of 2011. Nevertheless, patent suits by non-practicing entities (NPEs) have been on the increase over the past ten years. Major corporations, especially, such as Apple and Samsung have been on the receiving end of the litigation as NPEs target their large cash holdings. A closer look at the patent laws in the US and Europe reveals subtle differences in the grace period, publication of patent, and the application of patent rights across member states. Given the preceding facts, vital action points for the European market include the enactment of laws that prevent patent trolls as opposed to punishing NPEs after the act and reduction of litigation costs for lowquality patents.
\end{abstract}

KEYWORDS: patent trolls, US patent laws, intellectual property, differences between EU and US laws on Intellectual PropertyNon-Practicing Entities, Intellectual PropertyNon-Practicing Entities in Europe and the United States

\section{Introduction}

Patent trolls are more frequent in the intellectual property (IP) space than in other areas owing to the intangible nature of intellectual property. Helmers and McDonagh [1] attribute this phenomenon to the fact that it is easier to delineate physical property and define the owner's rights than it is with intellectual property. Considering that a patent is "an exclusive right granted to a party for an invention," IP presents an opportunity for individuals and businesses to manipulate the law and court processes [2]. While the practice is anchored in law, most patent trolls do not intend to develop or protect products as Helmers and McDonagh [1] explain. Instead, they aim at making profits and stifling competition. By conducting a thorough evaluation of patent trolls in the US economy, this study isolates crucial lessons that Europe can learn to prevent an escalation of the problem in Europe.

\section{Research background}

The patent system in the country has experienced a rise in patent litigation over the past decade. A 2012 study [3] examined the effects of intellectual property patents in the US. Results showed that business entities spent over \$29 billion in direct costs while defending against patent infringement claims. Between 2009 and 2013, for instance, Apple defended itself against 191 patent trolls; Samsung had 151, while Dell dealt with at least 140 [4]. Likewise, the situation in Europe depicts a rise in patent suits. A study [5] of 140 small businesses in Europe revealed that as of 2015, 44\% of them were affected by patent infringement cases by non-practicing entities (NPEs). These numbers presented here symbolize the actual circumstances on the ground, showing an urgent need to address patent trolling.

Such patent trolls affect the economy in wideranging means. The philosophy of Śledzik [4] shows that first; the sued party must spend more resources on legal fees. Second, the defendants lose significant market shares since lawsuits can adversely affect a company's reputation, on top of the legal overheads that are passed on to customers through price hikes [4]. Perhaps the highest cost is felt when the litigations impede the innovation process [3]. The US has made significant progress in tackling with the challenges over time. This paper applies the following research questions to identify fundamental lessons and action points for Europe. 
1. To what extent has legislation addressed the patent troll problem in the US?

2. What are the main differences between the US and European patent law systems that nonpracticing parties utilize to initiate patent litigations in Europe?

For this paper, we define certain terms as follows below.

Patent is a government-issued license that presents an inventor exclusive rights to the manufacture, use, or sale of the patented invention for a specified time period [6].

Non-practicing entities (NPEs) refers to sovereign organizations which own or benefit from patent rights but do not sell or manufacture goods or services associated with them and which have an aggressive assertion or litigative role as plaintiffs towards the enforcement of their patent rights. The organization holds a patent for a product or process without the intention of development [6].

Patent Troll. A patent troll refers to the deliberate effort by NPEs to acquire patent rights for use in suing other companies through licensing or litigation [6].

Intellectual Property. IP refers to the intangible category of property that encompasses human intellects such as trade secrets, trademarks, and publicity rights [3].

Patents cover different forms of inventions including processes and composition of matter. From the beginning, the US constitution sets the stage for patent suits in Article 1 Section 8 that state the role of the Congress in promoting innovation and useful arts by granting periods within which inventors can exercise the exclusive rights to their inventions. Bessen and Meurer [3], interpret this statement to mean an exclusive monopoly by the owner within which they can prevent third parties from using or selling the ideas. The owner's first obligation lies in filing a patent application through the US Patent and Trademark Office after developing an invention as the authors explain. Here, the party describes the innovation in precise terms to identify which aspects are protected under the law [7]. Patent infringement occurs when another party attempts to reproduce the product as described under the law whether intentionally or not.

Although patent laws have existed for decades, patent issues have only gained increased attention in recent years. The Court of Appeals for the Federal Circuit began conducting business in 1982, according to the Introduction to Intellectual Property: A U.S. Perspective [8]. Over the years, the country has made significant steps through constructing and refining patent laws. The formation of the Federal Appellate Court to attend to patent appeals and USPTO signified a substantial success in the area.
Consequently, it is now easier for patent holders to prove wilful infringement and harder for the accused to overthrow patents.

Recent interventions consist of the 2011 America Invents Act. The government intended to streamline the patent scene in the US with the rest of the world. The previous law allowed inventors to first invent the products and file during the later stages of development. Generally, the law meant that if two separate inventions were conceived at the same time, those that had the earlier date of invention received the protection. Today, the inventor who files the patent documents first gets the exclusive rights even if they do not have a previous time of invention [9]. While the change in the timelines is reasonable and achievable for most inventors, a closer look at the AIA reveals subtle counterbalances including a narrow prior art grace period, the initiation of proceedings, and a broader exception for research and shared ownership. Critics have pointed out the high fees required while filing a patent, which favours large corporations that have adequate funds to complete the processes within short periods in comparison to small businesses [10]. The argument is particularly valid for modern companies, which rely on outside funding to develop new products.

\section{Research methodology}

This paper uses the funnel research approach to conduct and analyse data from previous studies in support of the research questions. A thorough evaluation of the secondary sources was conducted to guarantee that each primary and secondary source is peer reviewed and that it presented data relevant to the study. Furthermore, the research presents the latest articles to assure utilization of the most recent data.

\section{Results}

The results section of the paper identifies issues in the US and European Union legislation which addresses the patent troll problem.

Despite the milestones that the US has made in combating the patent troll problem over the past decade, Cohen et al. [2] feel that the problem is yet to be adequately addressed. Four years after signing the AIA into law, 2015 recorded the highest number of patent troll cases in the country. The authors attribute this increase to the rise in technology commercialization, which precipitates action by businesses to protect their property. However, most of the cases involved NPEs whose sole intention is to create massive portfolios for use in suing other companies [3]. In a study to gauge the effectiveness 
of current laws in addressing the patent problem, Cohen and fellow authors [2] focused on measurable factors such as publicly traded firms, measures of firm characteristics, income, and patent holdings.

Results indicated that $59 \%$ of all patent litigations by NPEs have at least an invalid claim in comparison to $42 \%$ of the overall complaints. Second, Cohen and colleagues [2] noted a significant pattern that they named 'forum shopping'. The pattern consists of NPEs targeting certain business areas, which has a higher certainty of attaining a return in investment. For instance, Sillicon Valley recorded higher litigation dealing with patent trolls versus when compared to other industries. The NPEs also used location tactics, which have proven to be more effective. Certain US States that NPEs have deem to be plaintiff-friendly such as Texas have recorded significantly higher numbers than all other US States combined. Texas and the State of Delaware remain the most popular venues for NPE plaintiffs. The two venues accounted for $70 \%$ of all cases filed in the US and $66 \%$ of total defendants added. In the Cohen study [2], greater than $43 \%$ of all NPEs filed cases were filed in the state of Texas. Researchers observed that NPE litigations targeted companies with large cash holdings or whose fortunes had acquired them massive profits available in cash. Moreover, the study reflected that they also targeted firms with smaller legal teams with modest experience in the area. The focused-on companies that reported high profits, high cash holdings with smaller legal teams increased the potential return of investments in the litigations.

What are the main differences between the US and European patent law systems that non-practicing parties utilize to initiate patent litigation in Europe?

The Grace Period. The current US law preserves the old system's 1-year period that enables inventors at least a year to file the patent after acknowledging the invention in public. Previously, inventors could meet this objective by holding a press conference, giving a lecture about it, or presenting the idea to an investor among others [9].

Conversely, in the European Union, Kahnert [11] notes that some European Union countries attribute a 12-month grace period while others allow a six-month filing period. A 2014 study by the Europe Economic [12] investigated the significance of introducing a uniform grace period throughout the European Union. The results of the study demonstrated that the uniformed grace period would eliminate problems associated with accidental exposure of patents. Additionally, the grace period allowed the governing body additional time for market screening, testing, and improving the innovation.

Patent Publication. Article 112 of the US State code dictates that the publication of a patent must be done within 18 months of the filing date unless the owner no longer requires protection [13]. Further, the law also stipulates that a patent publication is unnecessary if the application for patent is accompanied by a non-publication request. This is a contrast between the US and European patent systems. In Europe, all patent publications are submitted within the 18-month period unless the owner withdraws the application. An earlier study [14] first confirmed the implication of the publication of the patent application law by stating that the information must remain in secret throughout the 18month period. The request clause in the US law means that the owner has an option to keep the information private and keep competition from accessing trade secrets.

The Application of Rights. Given that the patent law is a federal statute, patented content automatically gains protection throughout all the US states. Undoubtedly, this quality heightens the ease for holders to implement the license without the need to apply again in each state. Gates [6] compares this system to the European laws where the patent applies to the 27 countries included in the European Patent Convention. They include Switzerland, Monaco, Netherlands, Romania, and the United Kingdom among others. The European Patent Office (EPO), only grants rights applicable to the EPO countries that the holder specifies in the application. Additionally, according to the EPO, patents are valid in individual countries for specified periods. Patents, therefore, are subject to the laws found in each country. If an individual, for instance, needs to annul the patent, they must do so following the requirements of each country separately [15]. Efforts to address this problem encompass the enactment of the EU Unitary Patent Package of 2011. Still, criticism regarding the fragmentation of the European Union persists.

\section{Current US NPE related filings}

Patent litigation has evolved dramatically since patent reform litigation passed in 2011. However, the US has additional patent reform changes underway, new leadership at the US Patent and Trademark Office and high-profile (and potentially high impact) cases being considered by the Supreme Court in 2018. In 2017, NPE litigation filings continued a downward decrease from the peak in 2011. 2017, NPEs related litigations were 2,000, a decrease of $27 \%$ over last year. The legal changes since 2011 have made patent enforcement more difficult. Before the legal changes, an effective validity or eligibility defence typically awaited summary judgment and thus the completion of fact discovery in district court, which was a very expensive process. In 2018, a defendant can move to dismiss a case early, on the basis of ineligibility, or can file for post-grant review and seek to stay the litigation (including the discovery 
process) while the Patent Trial and Appeal Board (PTAB) reviews the validity of the patent. Both options have made patent validity a threshold issue and have reduced the cost of earlier litigation stages for defendants, thereby reducing plaintiffs' leverage early in the case. Despite the legal changes and reductions in NPE related legal filings, the quality characteristics of filings that result in more effective litigations have also increased. The assertion is derived from the observation that $59 \%$ of all patent litigations by NPEs had at least an invalid claim [2]. Also, the figures indicate a potential significant loophole in the current law since it fails to provide large corporates with the means to shield themselves from patent suits when targeted by NPEs. Cohen et al. [2] expressed an alarming trend regarding the forum shopping pattern. Also, seeing as the NPEs have identified states that they consider plaintifffriendly such as Texas and Delaware, laws in such states require modifications to eliminate this perception as explained by Cohen et al. [2].

Study results indicate that high-profile European companies have defended themselves against patent claims with an overall increased rate since 2010. In 2010, there were 760 cases filed by NPE's versus 1,555 in $2011,3,059$ in 2012, and 3,673 in 2013. In 2014, nearly 1,100 companies were first-time defendants in an NPE case, and when duplicates are removed from the list of defendants to any patent infringement case, 2014 saw about 3,800 unique defendants added. Large companies (by revenue) and public companies Current European Union NPE related filings have a higher rate of NPE litigation than do smaller and private companies. NPE litigation has remained the most common form of patent litigation in the EU. NPE cases accounted in 2014 for $63 \%$ of all such cases, and NPE defendants were $56 \%$ of all patent infringement defendants. The number of IPR petitions filed against NPE patents has increased over $150 \%$ from 2013 to 2014 (262 to 758). The report finds that, in the EU, NPEs prefer litigating in Germany. During the 2007-2017 period, $20 \%$ of infringement actions in Germany were NPE initiated. During the past ten years of European IP NPE related litigation has grown $19 \%$ every year, with an increased growth in 2014, 2015 and 2016.

Differences between the Two Patent Systems

The primary differences as presented in the data include disparities in the litigation grace period, the publication of patents, and the application of patent rights. The uniformity in the US system implies that a party only needs to apply for the patent with the federal government after which they can practice the rights in all the states within the country [9]. In contrast, countries within Europe ascribe to different grace periods ranging from six to twelve months, which complicates the holder's ability to practice their rights in individual countries. In the same breath, the disparity in the provision stated in the publication of patent provides additional leeway for NPEs to exploit. Furthermore, the European system leaves additional room for exploitation through its fragmented nature [6]. The fragmentation implies that although the EPO awards the patent, it is subject to the laws of a specific country in which the holder applies.

According to a report from the European Patent Office (EPO) [15], between 2007 and 2017, the average annual growth rate of actions related to NPEs was $19 \%$. Statistics reflect an annual increasing trend in the number of actions involving NPEs in the EU, with a dramatic increase in the last five years, primarily concerning information and communication technologies. The EPO report demonstrates that the five most active NPE company structures in the EU are based in the US. The legal filings account for $60 \%$ of NPE-related litigation in the EU. The increase in NPE litigation cases in the EU over the last five years, points to recent IP legislative changes in the US which have resulted in a reduction of prevailing cases by NPEs in the US. Similarly, to the US NPEs in the EU have a preference on where they litigate. While in the US NPEs prefer to file cases in Texas and Delaware; in the EU NPEs favour litigating cases in Germany. The EPO report reflects that during 2007 and 2017, twenty percent of infringement actions initiated by NPEs were in Germany. According to a legal review report by the German IP firm IAMMedia, Germany's legal and judicial framework is divided within the country and infringement and invalidity legal actions are independently ruled by different courts across the country. NPEs advantaged by the shortened IP legal time process of Germany while also benefiting from rulings which are often granted prior to the finalization of legal proceedings.

\section{Discussion}

The findings in this study indicate an urgent need to address illicit legal filings by NPEs in the EU through legal changes or transforming the IP marketplace. EU legal filings related to NPEs between 2007 and 2016 reflect a year-to-year increase of $19 \%$. A sharp increase in NPE cases in the EU over the last five years could be a result of recent legal changes in the US. As NPEs changed strategy, the German patent system with its brief litigation procedures and lack of up to date IP legal reforms, has emerged as the new hotspot to NPE activity. Germany lacks a pre-trial discovery or jury trials that the US provides in their system. In Germany, inspection proceedings are neither mandatory nor frequently used. Oral hearings (in comparison to trials) typically last only a few hours, rather than 
several days. Another attractive aspect to NTEs is the low costs of the German patent litigation, which is considerably lower than the US or other EU countries. Furthermore, following the Brexit referendum, uncertainty exists regarding the future of the EU's new unitary patent system, which further strengthens Germany's role as a leading venue for patent litigation.

Current laws in Europe do not address NPE litigations. While EU companies can file countersuits or attempt to mitigate their loss through existing proceedings, they take substantial loses in the litigation process and often in the disadvantageous courts which favour NPEs. Furthermore, NPEs are often shell companies that quickly dissolve and disappear without available financial resources that affected companies can go after for damages. In the US, the Innovation Act, for instance, requires mandatory fee-shifting to patent lawsuits to what the court terms reasonably justified [2]. The trends show that the law needs to provide added protection for large corporations with large cash holdings. As Cohen et al. [2], notes here is a pressing necessity especially in recognizing that cash holdings in segments unconnected to infringement drive NPE suits.

Another approach to the problem is to reduce the cost of defending against low-quality patents. In the US, a party can contest by claiming that the invention in question is original by showing prior art exists. However, filing such a challenge costs enormous amounts of money, meaning that easily disposable patents of such kind remain in force [2]. Also, the patent system in Europe could require that low-quality patents go through a court that conducts preliminary screening as the authors inform. An initial evaluation would likely unearth facts that can dismiss the case; that way, the advance review would help reduce NPE legal filings.

One of the primary strengths identified in the US patent system is the ability to apply patent laws equally among all the member states. Keep in mind that the significant shortcomings in the EU include differences in the grace period, publication, and the application of the application of the patent rights across member countries. By working towards an increasingly unified approach, Europe can significantly reduce the number of patent trolls [5].

Throughout the research, this study concurred with the findings by Bessen and Meurer [3] according to which the rate of patent litigation cases in the US increased significantly over the past decade despite the advancements in the legal landscape. The increase in the claims is attributed to the rise in technology advancements as companies move to protect their intellectual properties according to Cohen et al. [2]. The study also agrees with the findings by Cohen and fellow writers [2] that NPEs main aim while filing patent suits is to make profit rather than enhance innovations. The US has been at the forefront in developing laws regarding patent protection as depicted by Gates [6]. The study also validates the teachings by Cremers et al. [5] and The Europe Economic 2014 [12] that the Europe patent system falls short of addressing fragmentation. The departing point from the previous research presents when the study uses the milestones achieved in the US system to caution the Europe patent on the potential pitfalls and how the system can evade them.

\section{Conclusions}

Results indicate a subtle loophole in the current US law since it exposes large corporations to multiple patent suits when NPEs target their cash holdings. The primary differences between the two patent systems include disparities in the grace period, the publication of patents, and the application of patent rights. The fragmentation in the European patent system implies that although the EPO awards the patent, it is subject to the laws within the countries that the holder applies.

The findings in this study indicate an urgent need to reduce patent trolling by NPEs through changing the law or transforming the IP marketplace. The patent system in Europe could also require that low-quality patents go through a court that conducts preliminary screening. Additionally, by working towards a more unified approach, Europe can significantly reduce the number of patent trolls [5].

\section{References}

[1]. Helmers C., McDonagh L., Patent litigation in the UK: An empirical survey 2000-2008, Journal of Intellectual Property Law \& Practice, p. 846-861, 2013.

[2]. Cohen L., Gurun U. G., Kominers S. D., The growing problem of patent trolling, Journal of Science, p. 521-522, doi:10.1126/science.aad2686, 2016.

[3]. Bessen J. E., Meurer M. J., The direct costs from NPE disputes. Boston Univ. School of Law, Law and Economics Research Paper, no. 12-34, p. 1-59, doi:10.2139/ssrn.2091210, 2012.

[4]. Śledzik K., Patent trolls and Schumpeter's creative destruction, SSRN Electronic Journal, p. 89-96, doi:10.2139/ssrn.2424943, 2014.

[5]. Cremers K., Ernicke M., Gaessler F., Harhoff D., Helmers C., McDonagh L., Zeebroeck N., Patent litigation in Europe, European Journal of Law and Economics, p. 1-44, doi:10.1007/s10657-016-9529-0, 2017.

[6]. Gates C., Patenting the life sciences at the European patent office, Cold Spring Harbor Perspectives in Medicine, p. 212-221, doi:10.1101/cshperspect.a020792, 2014.

[7]. ***, AIPLA Report of the Economic Survey 2013, Arlington: American Intellectual Property Law Association (AIPLA), 2013.

[8]. Murphy A., Stramiello M., Lewis S., Irving T., Introduction to intellectual property: A U.S. perspective, Cold Spring Harbor Perspective Medicine, p. 1-15, doi:10.1101/cshperspect.a020776, 2015 . 


\section{THE ANNALS OF "DUNAREA DE JOS” UNIVERSITY OF GALATI \\ FASCICLE IX. METALLURGY AND MATERIALS SCIENCE \\ №. 3 - 2018, ISSN 2668-4748; e-ISSN 2668-4756 \\ Article DOI: https://doi.org/10.35219/mms.2018.3.09}

[9]. Hovenkamp H. J., The emergence of classical American patent law, Retrieved November 5, 2018, from Penn Law: Legal Scholarship Repository, 2016.

[10]. Lewis G., Opinion: Racing toward invention, The Scientist, p. 26-34. doi:10.1101/cshperspect.a026765, 2013.

[11]. Kahnert M., Inside views: Introduction of a grace period in Europe, Retrieved November 5, 2018.

[12]. ***, Europe Economic, The economic analysis of the grace period, Web: Europe Patent Office, 2014.
[13]. ***, USPTO, General information concerning patents, Retrieved November 5, 2018, from United States Patent and Trademark Office, 2018.

[14]. Cowan R., Eijik W. V., Lissoni F., Lotz P., OverWalle G. V., Schosvbo J., Policy options for the improvement of the European patent system, Retrieved November 5, 2018, from Scietific Techonolgy Options Assessment.

[15]. ***, EPO, Guide for applicants: How to get a European patent, Retrieved November 5, 2018, from EPO. 